\title{
Life saving collaterals: Right-to-left and left-to-right
}

\author{
Umut Kocabaşi ${ }^{1}$ Ferhat Özyurtlu², Bahadır Çöllü
}

\footnotetext{
1) Department of Cardiology, Soma State Hospital, Manisa, Turkey

${ }^{2)}$ Department of Cardiology, Grandmedical Hospital, Manisa, Turkey
}

\begin{abstract}
Coronary collaterals are anastomotic connections between portions of the coronary arteries. The coronary collateral circulation as an alternative source of blood suply has shown benefits such as limited infarct size, left ventricular remodelling and preserved left ventricular systolic functions.
\end{abstract}

Keywords: Coronary artery disease, collateral circulation, prevention.

Kocabaş U., Özyurtlu F. and Çöllü B. Life saving collaterals: Right-to-left and left-to-right

EJCM 2015; 03 (2): 24-26. Doi: 10.15511/ejcm.15.00224.

Copyright $(\odot 2015$ Heart and Health Foundation of Turkey (TÜSAV). Published by Medikal Akademi.

This article is licensed by Medikal Akademi and TÜSAV under the terms of Creative Commons Attribution License. 


\section{Case}

A 48 year-old male patient referred to cardiology clinic with typical anginal symptoms. There was not any remarkable disease in the patient's previous medical history. The 12-lead electrocardiogram showed ischemic changes. Transthoracic echocardiography showed mild hypokinesia in inferior wall, left ventricular ejection fraction was preserved and calculated 50\% with Simpson method. Coronary angiography revealed chronic total occlusion of right coronary artery (RCA) and left-anterior descending (LAD) artery both. Interestingly, coronary collaterals originate from proximal part of RCA were retrogradely filling the total occlused LAD and supplies enough flow to the LAD area at risk for infarction (Panel A, black arrows and asterisk). Following retrograde filling of LAD, septal collaterals which originated from the retrogradely filled LAD were seen to fill distal RCA retrogradely again and supplies enough flow to the RCA area at risk for infarction (Panel B-D, black arrows). Those united collaterals were suc- cessful at providing the blood supply, although with the chronic total occlusion of both RCA and LAD, a large area of myocardial ischemia was under at risk. The patient underwent coronary artery bypass graft surgery.

\section{Discussion}

Patients with coronary artery disease, coronary collateral circulation is associated with a reduction in infarct size, left ventricular dysfunction and cardiovascular events, which translates into a relevant improvement in survival. ${ }^{(1)}$ Well-developed coronary collaterals may help protect the myocardium from infarction during episodes of ischemia and may extend the limited number of valuable "golden hours" from the onset of an acute myocardial infarct to successful coronary reperfusion. ${ }^{(2)}$

In our case, myocardial salvage by extent collateral circulation is very likely in the presence of preserved left ventricular ejection fraction and protect heart from myocardial infarction despite the total occlusion of RCA and LAD.
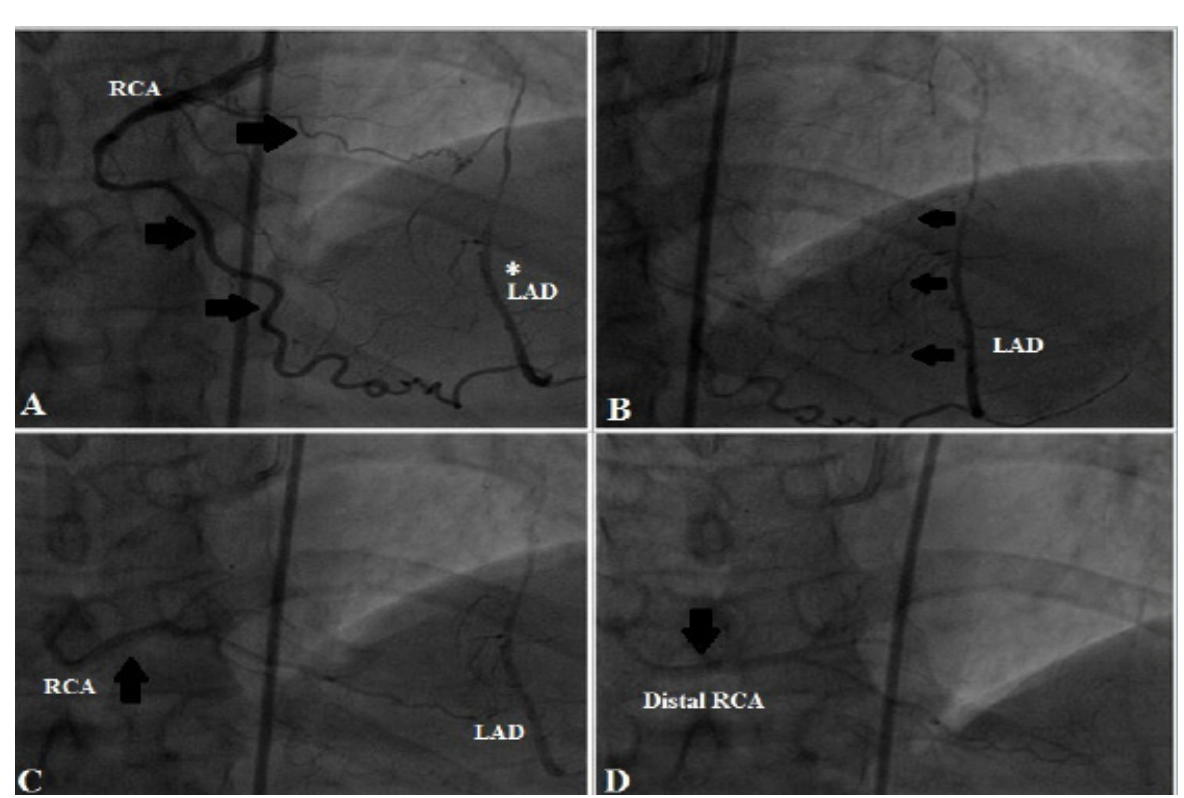

Figure legends:

Panel A-D: Collateral circulation originating from chronic total occluded right coronary artery (RCA) is retrogradely filling chronic total occluded left-anterior descending artery (LAD) (Panel A, black arrows and asterisk), septal collaterals developed from retrogradely filled LAD, supplying blood flow to the distal part of chronic total occluded RCA (Panel B, black arrows), distal RCA filling by septal collaterals originated from retrograd filled LAD again (Panel $\boldsymbol{C}-\boldsymbol{D}$, black arrows). 


\section{References}

1. Stoller M, Seiler C. Salient features of the coronary collateral circulation and its clinical relevance. Swiss Med Wkly 2015; 145:14154.

2. Koerselman J, van der Graaf Y, de Jaegere PP, Grobbee DE. Coronary collaterals: an important and underexposed aspect of coronary artery disease. Circulation 2003; 107:2507-11.
Received: 24/02/2015

Accepted: 11/09/2015

Published: $15 / 10 / 2015$

Disclosure and conflicts of interest:

Conflicts of interest were not reported.

\section{Corresponding author:}

Dr. Umut Kocabaş

Mail: umutkocabas@hotmail.com 